\title{
Partial median corpectomy for C2-C3 intradural arachnoid cyst: Case report and review of the literature
}

\author{
U. S. Srinivasan, Ashish Bangaari, G. Senthilkumar \\ Department of Neurosurgery, MIOT Hospitals, 4/112 Mount Poonamalle Road, Manapakkam, Chennai-600 089, Tamil Nadu, \\ India
}

\author{
Address for correspondence: \\ Dr. U.S. Srinivasan, M.Ch, \\ Chief Neurosurgeon, \\ 6 Hamsadwani Apartments, \\ $1^{\text {st }}$ Canal cross, Gandhinagar, Adyar, \\ Chennai - 600 020, Tamil Nadu, India. \\ E-mail: ussrini@vsnl.net
}

DOI: $10.4103 / 0028-3886.59484$

\begin{abstract}
Anterior cervical location of arachnoid cyst is a rare and only 22 cases have been reported in the literature. The surgical approach was Quite varied and mostly these cysts were accessed via dorsal laminectomy, with few patients developing postoperative neurological deficit. We report a 51 -year-old male with a cervical arachnoid cyst extending from the dens to the inferior border of the $\mathrm{C} 3$ body, which was successfully decompressed via an anterior cervical approach through the partial corpectomy of $\mathrm{C} 2$. This is probably the first case report demonstrating the safety of anterior partial median corpectomy of the $\mathrm{C} 2$ body with micro discectomy of $\mathrm{C} 2-\mathrm{C} 3$ space for excision of the anterior cervical archnoid cyst. The additional advantage of this procedure is that it may not result in spinal instability.
\end{abstract}

Key words: Arachnoid cyst, spinal cysts, anterior cervical approach, C2 corpectomy

\section{Introduction}

Anterior cervical location of arachnoid cyst is a rare entity and only 22 cases have been reported in the literature..$^{[1-14]}$ The majority of these cysts were operated by the posterior approach, using laminectomy and cyst excision, and with few cases developing postoperative neurological deficits. ${ }^{[1-12]}$ Here, we report a 51-year-old male with an anteriorly placed arachnoid cervical cyst extending from the dens to the inferior border of the C3 body, which was successfully decompressed via an anterior cervical approach through the partial corpectomy of C2.

\section{Case Report}

A 51-year-old male presented with neck pain aggravated by coughing, radiating to the front of the neck, for the last 4 months. It gradually progressed to weakness of the right upper limb, motor power grade $4 / 5$. Tendon reflexes were brisk in all the four limbs and planter was extensor bilaterally. There was no sensory deficit and the Romberg's sign was absent. His neck movements were also restricted.

Plain X-ray of the cervical spine was normal. Magnetic resonance imaging(MRI) scan of the cervical spine showed a well-defined smooth globular lesion located in the midline extending from the dens to the inferior border of the body of C3. The lesion was hypodense on T1-weighted image and hyperdense lesion on T2-weighted image, and there was no contrast enhancement. The cord was pushed posteriorly, with severe indentation anteriorly over the cervical spinal cord [Figure 1]. His blood parameters were normal.

\section{Surgical procedure}

Under general anesthesia in the supine position (neck extended and rotated 15 degrees to the left), an $8 \mathrm{~cm}$ curvilinear incision was made over the right side of the neck, starting from the midline, just below the chin and curving laterally below the level of the hyoid cartilage for $5 \mathrm{~cm}$. Through the standard anterior cervical approach ${ }^{[15,16]}$ after retracting the submandibular gland with its capsule, the prevertebral muscles were exposed. Under image guidance, the $\mathrm{C} 2-\mathrm{C} 3$ disc space was confirmed and after partial discectomy, the disc space was distracted using a Casper vertebral retractor. Microscopic discectomy was performed, including excision of the posterior osteophyte. Under image guidance, the posterior border of the $\mathrm{C} 2$ body and the 
dens-C2 body junction were confirmed. Over the $\mathrm{C} 2$ body, using monopolar cautery, a $10 \mathrm{~mm}$ height and $10 \mathrm{~mm}$ width area of corpectomy to be performed was marked, with the center of it in the middle of the $\mathrm{C} 2$ body and the base at the level of the inferior border of the $\mathrm{C} 2$ body. Partial midline C 2 corpectomy was performed. The upper limit of the corpectomy was $5 \mathrm{~mm}$ below the dens-C2 body junction. The dura was opened in an ' $X$ '-shaped manner and the anterior part of the cyst membrane, which was transparent and bluish in color bulged out. It was gently dissected on all sides and partially excised after draining the clear cyst fluid. No attempt was made to remove the posterior aspect of the cyst membrane attached to the cervical spinal cord. Using a patch of muscle tissue combined with surgicel, the dural opening was sealed because it could not be sutured. After obtaining complete hemostasis, the wound was closed in layers with a drain.

In the immediate postoperative period, he had transient dysphagia and hoarseness of voice which improved within a week, He also developed a soft fluctuant swelling in the right submandibular region, which subsided with conservative treatment in 2 weeks. In view of the submandibular region swelling, the patient was observed in the hospital for 10 days and he did not have any respiratory distress. There was rapid recovery in his neurological status. At 18 months follow-up, the patient was asymptomatic and returned back to work. His postoperative MRI revealed a small residual arachnoid cyst [Figures 2 and 3] behind the body of C-2. Postoperative dynamic radiographs of the cervical spine performed periodically did not reveal any instability at the C2-C3 level [Figure 4] and he is being followed-up.

\section{Discussion}

Anteriorly situated cervical intradural arachnoid cysts are rare. Review of the literature reveals only 22 reported cases, 13 children and nine adults..$^{[1-14]}$ Our patient was aged 51 year at the time of presentation, which is rather an unusual age of presentation Of the 22 cases reported in the literature, 20 cases have been operated through the posterior approach using laminectomy.$^{[1-14]}$ In these cases, either total ${ }^{[6]}$ or partial cyst excision, ${ }^{[2]}$ fenestration, ${ }^{[2,7,11]}$ needle aspiration, ${ }^{[1]}$ cystoperitoneal $^{[7]}$ or cystopleural ${ }^{[7]}$ shunt and percutaneous fenestration ${ }^{[4]}$ have been performed. This operative approach has resulted in postoperative neurological deficit in a few cases ${ }^{[14]}$ and the need for performing extensive laminectomies in the large cyst $[6,8]$ The case who had needle aspiration of the cyst died. ${ }^{[1]}$ The remaining two cases with the arachnoid cyst located below C3 level had excision of the cyst done through the anterior approach with corpectomy and reconstruction. ${ }^{[13,14]}$

Anterior cervical approach is a well-known approach with fewer complications. ${ }^{[13-16]}$ Performing a C3 and C2 complete corpectomy, including the dens, to

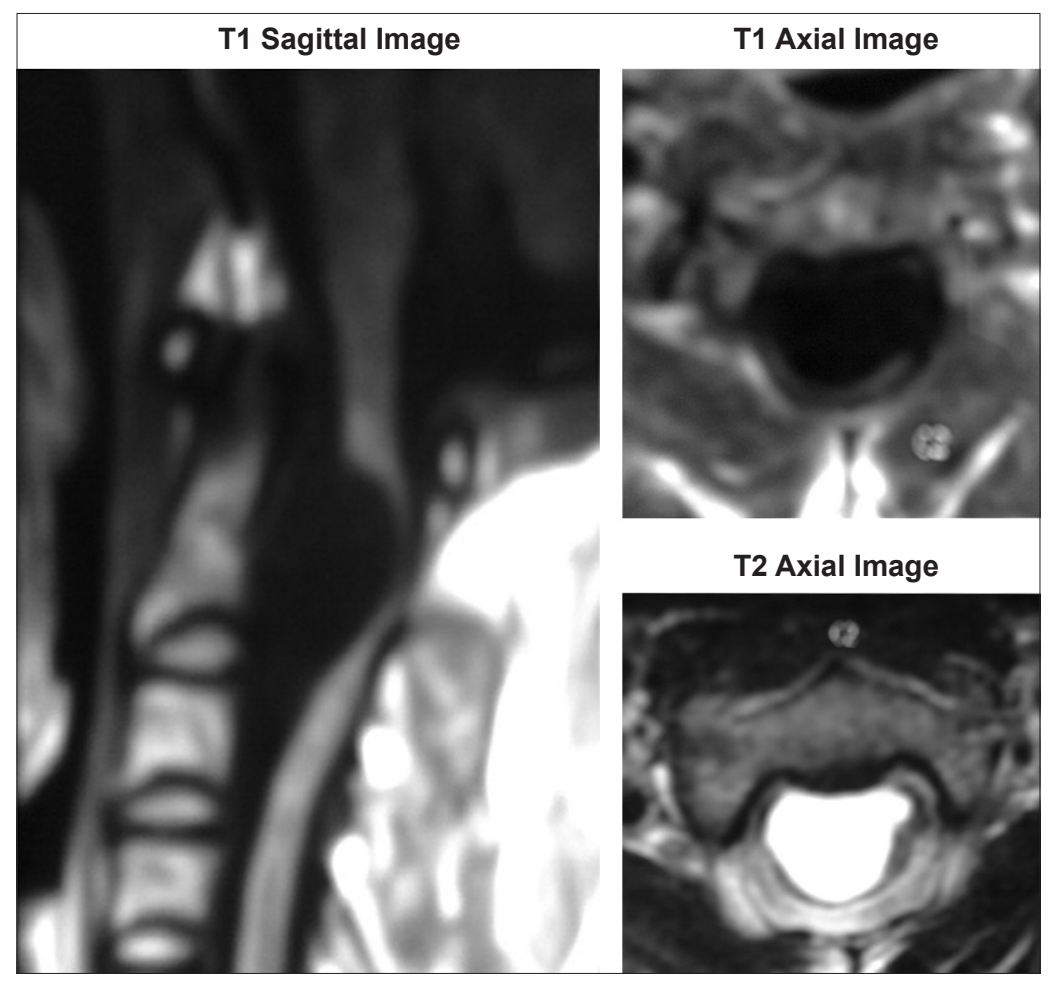

Figure 1: Preoperative magnetic resonance imaging T1 and T2 images showing the arachnoid cyst in the cervical region anterior to the cervical spinal cord 


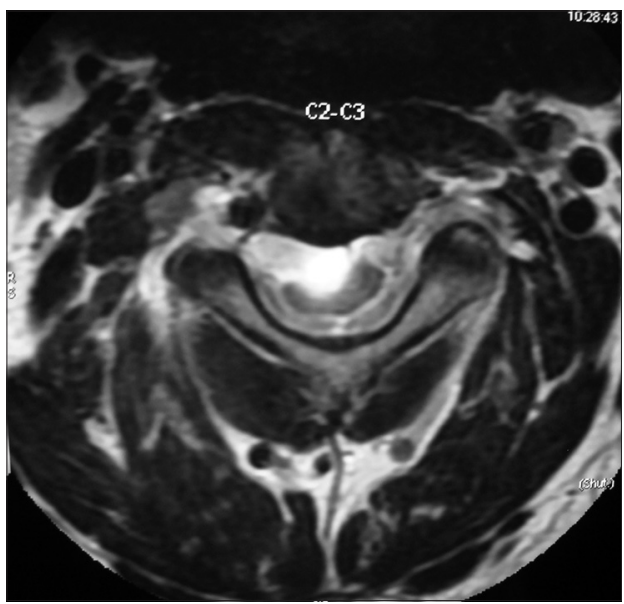

Figure 2: Postoperative magnetic resonance imaging axial section T2 image showing a small residual arachnoid cyst in the cervical region anterior to the cervical spinal cord

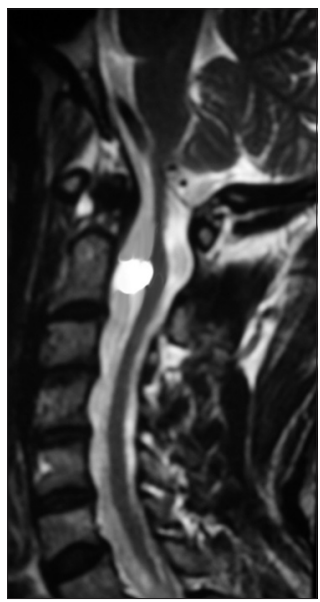

Figure 3: Postoperative magnetic resonance imaging sagittal section T2 image showing a small residual arachnoid cyst in the cervical region anterior to the cervical spinal cord

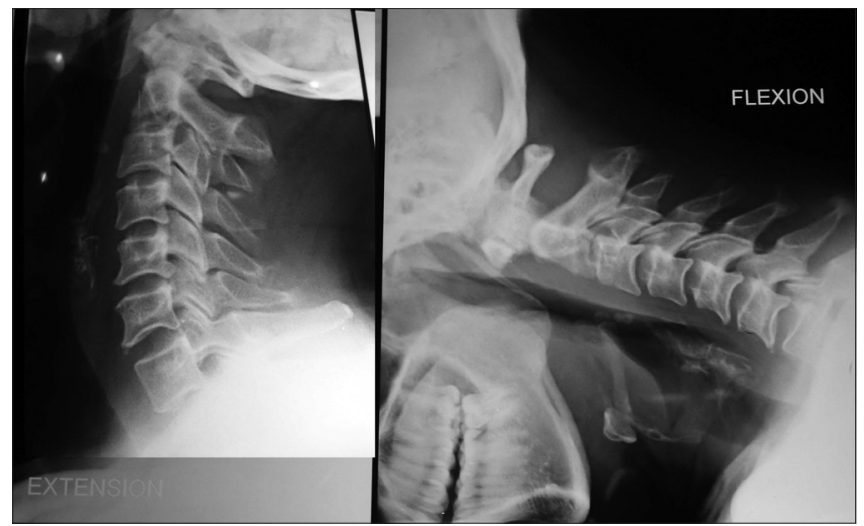

Figure 4: Postoperative $X$-ray of the cervical spine in flexion and extension views showing no evidence of instability at the $\mathrm{C} 2-\mathrm{C} 3$ junction

approach a lesion located behind the $\mathrm{C} 3$ and $\mathrm{C} 2$ body would lead to gross instability of the craniovertebral junction and would require a stabilization procedure. Here, we advocate excision and drainage of the anterior wall of the cyst through C2-C3 discectomy and partial median corpectomy of the $\mathrm{C} 2$ body without disturbing the dens-C2 body junction, pedicle or facet joints. There was no evidence of instability on long-term follow-up in our case. In a majority of the cases, only partial excision or drainage has been performed, with good long-term outcome..$^{[2,7]}$ Our case shows that via the anterior approach, the lesion can be accessed safely without any need for intraoperative manipulation of the spinal cord. Also, the anterior wall can successfully be excised partially leading to good postoperative recovery. This is the first case report in the literature showing that anterior partial median corpectomy of the $\mathrm{C} 2$ body with microdiscectomy of the C2-C3 space could be performed safely and that the cystic lesion behind the $\mathrm{C} 2-\mathrm{C} 3$ body could be excised without causing instability or requiring an additional stabilization procedure.

\section{References}

1. Palmer JJ. Cervical intradural arachnoid cyst in a 3-year-old child. Report of a case. Arch Neurol 1974;31:214-5.

2. Kazan S, Ozdemir O, Akyuz M, Tuncer R. Spinal intradural arachnoid cysts located anterior to the cervical spinal cord. Report of two cases and review of the literature. J Neurosurg 1999;91:211-5.

3. Safriel YI, Sanchez G, Jhaveri HS. Giant anterior cervicothoracic arachnoid cyst. Spine 2002;27:366-8.

4. Takahashi S, Morikawa S, Egawa M, Saruhashi Y, Matsusue Y. Magnetic resonance imaging-guided percutaneous fenestration of a cervical intradural cyst. Case report. J Neurosurg 2003;99:313-5.

5. Muthukumar N. Anterior cervical arachnoid cyst presenting with traumatic quadriplegia. Childs Nerv Syst 2004;20:757-60.

6. Hamamcioglu MK, Kilincer C, Hicdonmez T, Simsek O, Birgili B, Cobanoglu S. Giant cervicothoracic extradural arachnoid cyst: Case report. Eur Spine J 2006;15:595-8.

7. Maiuri F, Laconetta G, Esposito M. Recurrent episodes of sudden tetraplegia caused by an anterior cervical arachnoid cyst. J Neurol Neurosurg Psych 2006; 77:1185-6.

8. Shehu BB, Hassan I. Cervicothoracic arachnoid cyst in a patient with neurofibromatosis: Case report. East Afr Med J 2006;83:515-7.

9. Aslan G, Mehmet T, Fahri Y, Murad B. Unusual presentation of cervical spinal intramedullary arachnoid cyst in childhood: Case report and review of literature. Pediatric Neurosurg 2007;43:50-3.

10. Kutlay M, Oolak A, Demircan N, Akin O. Craniocervical junction arachnoid cyst causing hydrocephalus: Case report and review of the literature. Mil med 2007;172:669-72.

11. Jain F, Chaichana KL, McGirt MJ, Jallo GI. Neonatal anterior cervical arachnoid cyst: Case report and review of the literature. Childs Nerv Syst $2008 ; 24: 965-70$

12. Gezici AR, Ergun R. Cervical anterior intradural arachnoid cyst in a child. Acta Neurochir (Wien) 2008;150:695-98

13. Banczerowski P, Lipoth L, Vajda J, Veres R. Surgery of ventral intradural midline cervical spinal pathologies via anterior cervical approach: Our experience. Ideggyogy Sz 2003;56:115-8

14. Muhammedrezai S, Ulu MO, Tanrivover N, Moghaddam AM, Akar Z. Cervical intradural ventral arachnoid cyst resected via anterior corpectomy with reconstruction: A case report. Turk Neurosurg $2008 ; 18: 241-4$

15. McDonnel DE, Harrison SJ. Anterolateral cervical approach to the Craniovertebral junction. In: Wilkins RH, Rengachary SS, eds. Neurosurgery $2^{\text {nd }}$ ed. New Delhi: McGraw Hill Co; 1996:1641-53.

16. Laheri VJ, Ramani PS. Transcervical approach to the anterior cranio-vertebral junction. In: Ramani PS ed. Text book of Spinal Surgery. Mumbai: Bhooma Graphics Ltd; 1996:719-23.

Accepted on 04-10-2009

Source of Support: Nil, Conflict of Interest: None declared. 